\title{
Caracterização da matéria orgânica dissolvida em processos de tratamento de água para consumo humano usando fracionamento rápido
}

\author{
Characterization of dissolved organic matter in drinking \\ water treatment processes using rapid fractionation
}

Felipe José Hillebrand’ $₫$, Antônio Domingues Benetti*

口

\begin{abstract}
RESUMO
Matéria orgânica natural (MON) éuma complexa matriz de compostos orgânicos originados de fontes naturais que estão presentes em corpos hídricos. A MON é comprovada precursora de subprodutos da desinfecção (SPD), além de afetar processos de tratamento de água, tais como a coagulação, a desinfecção, a oxidação, a adsorção em carvão ativado e a filtração em membranas. Por essas razões, a redução da MON no tratamento de água para consumo humano é importante. Vários métodos são usados para caracterizar e quantificar a MON, tais como adsorção em resinas e parâmetros de massa. Carbono orgânico total (COT), carbono orgânico dissolvido (COD), absorção na região do ultravioleta $\left(U_{254}\right)$ e absorbância específica de luz ultravioleta (AEUV) são usualmente utilizados como parâmetros de massa. O fracionamento rápido é uma técnica que usa diferentes resinas para separar frações da MON. Nesse contexto, este trabalho teve como objetivo geral caracterizar a matéria orgânica dissolvida (MOD) em processos de tratamento de água para consumo humano usando o método do fracionamento rápido e os parâmetros COD, $U_{254}$ e AEUV. Também foram analisados as variáveis turbidez, cor, pH e alcalinidade. Foram avaliados os efeitos dos processos de coagulação, sedimentação, filtração e adsorção em carvão ativado nas frações que formam a MON. Ácidos muito hidrofóbicos (AMH) constituíram a principal fração da MOD na água estudada, havendo redução de 89\% entre a água bruta e o efluente do filtro de carvão ativado granular (CAG). A segunda fração predominante foi de ácidos levemente hidrofóbicos (ALH), reduzidos em $83 \%$ ao longo do tratamento. Na água bruta, as frações de matérias hidrofilicas carregadas (MHC) e de neutras (MHN) apresentaram concentrações de $0,11 \mathrm{mg} \mathrm{L}^{-1}$ e 0,04 $\mathrm{mg} \mathrm{L}^{-1}$, não sendo removidas pelo tratamento.
\end{abstract}

Palavras-chave: matéria orgânica dissolvida; fracionamento rápido, ácidos muito hidrofóbicos; ácidos levemente hidrofóbicos; matérias hidrofílicas carregadas, matérias hidrofílicas neutras.

\begin{abstract}
Natural organic matter (NOM) is a complex matrix of organic compounds originated from natural sources that are present in water bodies. NOM is a known precursor of disinfection by-products (DBP) and affects drinking water treatment processes such as coagulation, disinfection, oxidation, activated carbon adsorption, and membrane filtration. For these reasons, the reduction of NOM in water treatment is important. Several methods are used to characterize and quantify NOM, such as resin adsorption and mass parameters. The latter include total organic carbon (TOC), dissolved organic carbon (DOC), ultraviolet absorption at $254 \mathrm{~nm}\left(\mathrm{UV}_{254}\right.$ ) and specific UV absorption (SUVA). Rapid fractionation is a technique that uses different resins to separate NOM fractions. The objective of this study was to characterize dissolved organic matter (DOM) in drinking water treatment processes using rapid fractionation and the parameters DOC, $U V_{254}$ and SUVA. Turbidity, color, pH, and alkalinity were also analyzed. The effects of coagulation, sedimentation, filtration, and adsorption processes on the fractions forming the NOM were evaluated. Very hydrophobic acids (VHA) constituted the main fraction of DOM in the studied water, with a reduction of $89 \%$ between raw water and granular activated carbon filter (GAC) respect to raw water. The second predominant fraction consisted of slightly hydrophobic acids (SHA), reduced by $83 \%$ throughout the treatment processes. In raw water, the hydrophilic charged (MHC) and neutral (MHN) fractions showed concentrations of 0.11 and $0.04 \mathrm{mg} \mathrm{L}^{-1}$, which were not removed during treatment.
\end{abstract}

Keywords: dissolved organic matter; rapid fractionation; very hydrophobic acids; slightly hydrophobic acids; charged hydrophilic matters; neutral hydrophilic matters. 


\section{INTRODUÇÃO}

A matéria orgânica natural ( $\mathrm{MON})$ compreende complexa matriz de compostos orgânicos oriundos de fontes naturais e que estão presentes em corpos de água (CRITTENDEN et al., 2012). As estruturas químicas de tais compostos orgânicos ainda não são totalmente definidas, mas incluem substâncias alifáticas e aromáticas fortemente coloridas (MATILAINEN; VEPSÄLÄINEN; SILLANPÄÄ, 2010; EDZWALD; TOBIASON, 2011; MATILAINEN et al., 2011; CRITTENDEN et al., 2012). Além da variedade de constituintes químicos, a MON apresenta diferentes tamanhos moleculares (THURMAN, 1985; SWIETLIK et al., 2004). Sua composição elementar inclui cerca de 45 a 60\% de carbono, 4 a 5\%de hidrogênio, 35 a 40\% de oxigênio e 1\% de nitrogênio (THURMAN, 1985).

A remoção de $\mathrm{MON}$ em águas de abastecimento é importante porque ela afeta os processos de tratamento de água para consumo humano, além de ser precursora de subprodutos da desinfecção (EDZWALD; TOBIASON, 2011; CRITTENDEN et al., 2012). Vários processos são empregados para a remoção de MON no tratamento de água, incluindo a coagulação, a coagulação aprimorada e/ou otimizada, a adsorção em carvão ativado e em resinas de troca iônica magnética $\left(\right.$ MIEX $\left.^{\circledast}\right)$, a filtração em membranas, os processos oxidativos avançados (POAs), o biotratamento e a ozonização (MATILAINEN; VEPSÄLÄINEN; SILLANPÄÄ, 2010; BOND et al., 2011; MATILAINEN et al., 2011; CRITTENDEN et al., 2012; SILLANPÄÄ, 2015).

Os processos mais comuns e economicamente viáveis para a remoção de MON são a coagulação e a floculação, seguidas de sedimentação/flotação e de filtração por areia. O dois primeiros processos são eficazes para a remoção de matérias orgânicas hidrofóbicas de alto peso molecular (APM), tais como os ácidos húmicos. Contudo, os processos são limitados com relação à remoção de compostos hidrofílicos de tamanhos menores (MATILAINEN; VEPSÄLÄINEN; SILLANPÄ̈̈, 2010; MATILAINEN et al., 2011; TREGUER et al., 2010; SILLANPÄ̈̈, 2015). Com relação à adsorção em carvão ativado granular (CAG), a remoção de MON decorre em três formas principais:

- $\quad$ adsorção de MON solúvel;

- filtração física de partículas de $\mathrm{MON}$;

- biodegradação de MON, caso um biofilme ativo se desenvolva nas partículas de CAG (GIBERT et al., 2013).

Métodos usados na caracterização de MON compreendem adsorção em resinas, cromatografia de exclusão por tamanho (SEC), espectroscopia de ressonância magnética nuclear $(\mathrm{RMN})$ e espectroscopia de fluorescência. Já a quantificação de MON na água tem sido estimada sobretudo por parâmetros substitutos, como carbono orgânico total (COT) e carbono orgânico dissolvido (COD), absorção de luz ultravioleta em $254 \mathrm{~nm}\left(\mathrm{UV}_{254}\right)$ e absorbância específica de luz ultravioleta (AEUV) (EDZWALD; TOBIASON, 2011; MATILAINEN et al., 2011; APHA; AWWA; WEF, 2012).
O fracionamento rápido é uma técnica usada para a caracterização da MON. Essa técnica utiliza três resinas de troca iônica (DAX-8, XAD-4 e IRA-958) para separar a MON em quatro frações orgânicas: ácidos muito hidrofóbicos (AMH), ácidos levemente hidrofóbicos $(\mathrm{ALH})$, matérias hidrofílicas carregadas (MHC) e matérias hidrofílicas neutras (MHN) (CHOW; FABRIS; DRIKAS, 2004; VIEIRA et al., 2012). Essas frações são definidas quanto às resinas adsorventes:

- AMH: A fração de MON que é adsorvida pela resina DAX-8;

- ALH: A fração de MON que é adsorvida por XAD-4;

- MHC: A fração de MON que é adsorvida por IRA-958;

- MHN: A fração de MON que não é adsorvida por nenhuma das resinas (EIKEBROKK; JUHNA; ØSTERHUS, 2006).

De acordo com Thurman (1985), os ácidos hidrofóbicos constituem aproximadamente $50 \%$ do carbono orgânico total na água, são constituídos de ácidos húmicos, fúlvicos e de humina e apresentam carbono aromático, ligações duplas conjugadas e estruturas fenólicas, variando em peso molecular e em grupos funcionais. A matéria hidrofílica contém compostos alifáticos de carbono e nitrogênio, como carboidratos, açúcares, proteínas e aminoácidos.

O objetivo deste trabalho foi utilizar a técnica de fracionamento rápido para caracterizar e quantificar o efeito dos processos de coagulação, sedimentação, filtração granular em areia e adsorção em CAG na remoção da MON de água usada em uma estação de tratamento em escala real. Essa caracterização foi feita com análises de carbono orgânico dissolvido e absorção de luz ultravioleta em $254 \mathrm{~nm}$.

\section{METODOLOGIA}

\section{Água de abastecimento utilizada}

A água utilizada nos ensaios foi coletada na estação de tratamento de água (ETA) Moinhos de Vento, pertencente ao Departamento Municipal de Água e Esgotos de Porto Alegre (DMAE). Essa ETA trata águas do lago Guaíba por meio de tratamento de ciclo completo, com coagulação, floculação, decantação, filtração granular em areia e desinfecção com cloro. A água recebe ainda fluoretação e alcalinização. Em períodos mais críticos de qualidade de água, utiliza-se carvão ativado pulverizado. Na captação de água é acrescentado dióxido de cloro para controle do mexilhão dourado. $\mathrm{O}$ atual ponto de captação de água bruta da estação está situado no Lago Guaíba, junto ao Canal Navegantes (PMPA, 2013). A qualidade da água no local é classificada como regular ou ruim pelo indice de qualidade da água (IQA) usado pelo DMAE (2012). Isso se deve principalmente à contribuição do rio Gravataí, que é contaminado por esgotos domésticos. Os problemas com floração de algas no lago Guaíba ocorrem sobretudo nos meses de verão, em virtude de temperaturas mais altas, dias com mais horas de insolação e menor pluviometria. 
As características do processo de tratamento da ETA Moinhos de Vento estão descritas na Tabela 1.

$\mathrm{Na}$ ETA analisada, encontram-se também instalados dois filtros experimentais pilotos de CAG. Eles foram projetados para receber cerca de 2,0 $\mathrm{L} \mathrm{min}^{-1}$ de água, que passa pelos filtros granulares de areia. Em função das flutuações de níveis nos filtros de areia, as vazões para o CAG variavam entre 0,8 e 1,5 L min ${ }^{-1}$. Os filtros CAG estão contidos em duas colunas feitas de acrílico, com diâmetro de $0,15 \mathrm{~m}$, preenchidas com 0,20 m de material suporte e com 1,0 m de CAG - sendo utilizado o Carbono 119, feito de casca de coco produzido pelas Indústrias Químicas Carbomafra S.A., de Curitiba, PR (Tabela 2). O tempo de contato de leito vazio variou entre 12 e 22 minutos. As colunas de CAG foram instaladas em área protegida de iluminação solar para evitar o crescimento de algas.

\section{Coletas realizadas e pontos de amostragem de água}

Foram realizadas três coletas, nos dias 27 de julho, 29 de agosto e 13 de outubro de 2016. Nas duas primeiras coletas, a água potável de Porto Alegre estava com presença de gosto e odor, mas a causa não foi atribuída a algas e a cianobactérias, uma vez que não havia floração. Houve suspeita de

Tabela 1 - Características dos processos de tratamento da estação de tratamento de água Moinhos de Vento.

\begin{tabular}{l|c} 
Características do processo \\
Coagulação & Sulfato de alumínio/cloreto de polialumínio (CPA) \\
\hline Floculação & Fluxo hidráulico \\
\hline Decantação & Convencional \\
\hline Filtração & Filtração rápida por gravidade em leito de areia \\
\hline Desinfecção & $\begin{array}{c}\text { Gás cloro, sistema de injeção para } \\
\text { intercloração e pós-cloração }\end{array}$ \\
\hline Fluoretação & Ácido fluossilícico \\
\hline Alcalinização & Hidróxido de sódio \\
\hline $\begin{array}{l}\text { Remoção de } \\
\text { micropoluentes }\end{array}$ & Carvão ativado em pó, dióxido de cloro \\
\hline
\end{tabular}

Fonte: adaptado de PMPA, 2013

Tabela 2 - Características do carvão ativado granular 119.

\begin{tabular}{|c|c|c|}
\hline \multicolumn{2}{|l|}{ Característica } & Valor \\
\hline \multicolumn{2}{|c|}{ Número de iodo $\left(\mathrm{mg} \mathrm{I}_{2} \mathrm{~g}^{-1}\right)$} & 883 \\
\hline \multicolumn{2}{|c|}{ Coeficiente de uniformidade (-) } & 1,59 \\
\hline \multicolumn{2}{|c|}{ Area superficial BET $\left(\mathrm{m}^{2} \mathrm{~g}^{-1}\right)$} & 1.218 \\
\hline \multirow{4}{*}{$\begin{array}{l}\text { Distribuição } \\
\text { dos poros } \\
\text { (\%) }\end{array}$} & Microporos Primários (poro < 0,8nm) & 54,1 \\
\hline & Microporos Secundários (0,8 nm < poro < 2 nm) & 34,5 \\
\hline & Mesoporos (2 nm $\leq$ poro < 50 nm) & 8,8 \\
\hline & Macroporos (50 nm < poro) & 2,6 \\
\hline
\end{tabular}

BET: Brunauer, Emmett e Teller.

Fonte: adaptado de TEIXEIRA, 2014. despejo industrial e foi feito monitoramento na área de captação de água, pela Fundação Estadual de Proteção Ambiental do Rio Grande do Sul, com 12 coletas entre 13 de julho e 27 de setembro de 2016 (DORNELES; MIDUGNO; RODRIGUES, 2017). De acordo com esse trabalho, o local do ponto de captação apresentou condições favoráveis para abastecimento público com relação a $\mathrm{DBO}\left(1,0\right.$ a 3,0 $\left.\mathrm{mg} \mathrm{L}^{-1}\right)$, Escherichia coli (<1.000 NMP $\left.100 \mathrm{~mL}^{-1}\right)$, fósforo total $\left(0,05 \mathrm{a} 0,2 \mathrm{mg} \mathrm{L}^{-1}\right)$, nitrogênio amoniacal $(0,01$ a $\left.1,0 \mathrm{mg} \mathrm{L}^{-1}\right)$ e oxigênio dissolvido $\left(6,0\right.$ a $\left.8,8 \mathrm{mg} \mathrm{L}^{-1}\right)$.

As amostras de água foram tomadas nos seguintes pontos:

- água bruta na entrada da ETA;

- água na saída dos decantadores;

- água após passar por filtro granular de areia;

- água após passar por um dos filtros de CAG.

No total, foram coletadas doze amostras simples, colocadas em frascos plásticos de $1.000 \mathrm{~mL}$. As amostras de $\mathrm{pH}$, cor, turbidez e alcalinidade foram determinadas em até 24 horas. Os volumes separados para COD, absorbância e fracionamento rápido foram armazenados a $4^{\circ} \mathrm{C}$ e medidos em até 25 dias após a coleta.

\section{Métodos analíticos}

As amostras de água coletadas foram analisadas para os parâmetros turbidez, cor, pH, alcalinidade, absorção em UV, COD e AEUV, conforme métodos analíticos apresentados em Standard Methods for the Examination of Water and Wastewater (APHA; AWWA; WEF, 2012). A turbidez foi determinada com turbidímetro marca Hach, modelo $2100 \mathrm{~N}$. A cor e o $\mathrm{pH}$ foram medidos, respectivamente, por colorímetro Digimed, modelo DM-COR e pHmetro Digimed, modelo DM-22. A alcalinidade foi analisada por meio de via úmida titulométrica. A absorção na região do UV em $254 \mathrm{~nm}$ foi determinada por meio de espectrofotômetro, marca Pró-Análise, modelo UV-1600. O COD foi mensurado com analisador de carbono orgânico, marca Shimadzu, modelo TOC-L CPH. A AEUV foi calculada pela Equação 1:

$\mathrm{AEUV}=\left(\mathrm{UV}_{254} / \mathrm{COD}\right) \times 100$

Em que:

AEUV = absorbância específica de luz UV $\left(\mathrm{L} \mathrm{mg}^{-1} \mathrm{~m}\right)$;

$\mathrm{UV}_{254}=$ absorção de luz em UV a $254 \mathrm{~nm}\left(\mathrm{~cm}^{-1}\right)$;

$\mathrm{COD}=$ concentração de carbono orgânico dissolvido $\left(\mathrm{mg} \mathrm{L}^{-1}\right)$.

A análise de variância (ANOVA), fator duplo sem repetição, foi usada para identificar possíveis diferenças entre os tratamentos (água bruta, água decantada, filtração granular de areia e filtração em coluna de CAG) e as datas das coletas (27 de julho de 2016, 29 de agosto de 2016 e 13 de outubro de 2016), para os parâmetros analisados. ANOVA foi realizada em Microsoft Office Excel ${ }^{\circledR}$. 


\section{Fracionamento rápido}

$\mathrm{O}$ fracionamento rápido foi feito de acordo com a metodologia descrita em Chow, Fabris e Drikas (2004). O procedimento consistiu na passagem das amostras de água em colunas preenchidas com três resinas adsorventes (DAX-8, XAD-4 e IRA-958, marca Supelco), resultando em quatro frações: AMH (adsorvida por DAX-8), ALH (adsorvida por XAD-4), MHC (adsorvida por IRA-958) e MHN (que não se adsorveu em nenhuma das resinas).

\section{Preparo das resinas}

As resinas de troca iônica adsorventes (DAX-8, XAD-4 e IRA-958) foram preparadas antes das coletas de cada conjunto de amostras. Esse preparo foi feito com o uso de metanol grau HPLC, acetonitrila grau HPLC e água deionizada, conforme protocolo descrito em Westphalen e Benetti (2016), com base no procedimento descrito em Chow, Fabris e Drikas (2004). Após o preparo, as resinas eram transferidas para três colunas de vidro de $20 \mathrm{~cm}$ de altura e $13 \mathrm{~mm}$ de diâmetro interno, possuindo um volume de $26,53 \mathrm{~cm}^{3}$. Cada resina era colocada dentro de uma coluna diferente.

\section{Filtragem das amostras}

Posteriormente às coletas, as amostras de água foram filtradas a vácuo em filtros de membrana de nitrocelulose com diâmetro de $0,45 \mu \mathrm{m}$ e encaminhadas para o fracionamento rápido. Volumes de $600 \mathrm{~mL}$ eram filtrados e usados no fracionamento. Depois de filtradas, as diferentes amostras (filtro de carvão ativado, filtro de areia, água decantada e água bruta) eram acondicionadas em frascos plásticos e armazenadas a $4^{\circ} \mathrm{C}$ na geladeira. $\mathrm{O}$ fracionamento rápido começava a ser feito em até dois dias após as coletas de água na ETA.

\section{O procedimento do fracionamento rápido}

Para o procedimento do fracionamento rápido, a vazão aplicada às colunas com resinas foi de aproximadamente 3,0 $\mathrm{mL} \mathrm{min}^{-1}$, considerando a otimização do procedimento realizado por Chow, Fabris e Drikas (2004). Nesse caso, o tempo de duração do fracionamento rápido, excluindo ajustes de $\mathrm{pH}$ e de vazão, foi 6 horas e 10 minutos. Durante a passagem das amostras nas colunas, faziam-se também medições de vazões da água que saía delas.

O fracionamento das amostras foi realizado em sequência, passando-se primeiro pelas colunas, a amostra hipoteticamente mais limpa. Essa sequência foi:

1. efluente do filtro de carvão ativado;

2. efluente do filtro de areia;

3. água decantada;

4. água bruta.

As resinas usadas em cada conjunto de amostras foram descartadas e novas resinas foram preparadas para o segundo e para o terceiro conjuntos.

A Figura 1 ilustra o procedimento do fracionamento rápido. A amostra de $600 \mathrm{~mL}$, selecionada para o fracionamento, que foi anteriormente

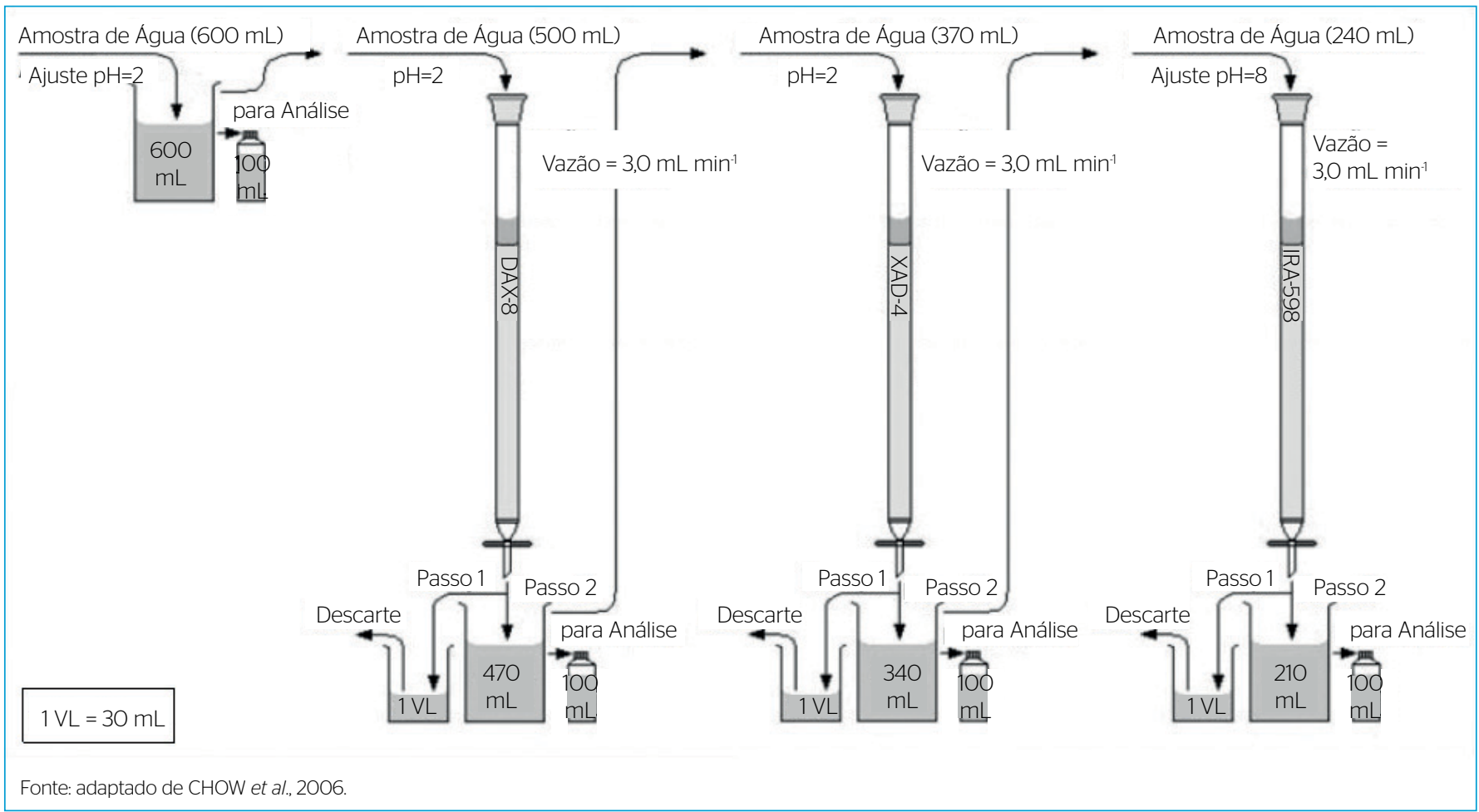

Figura 1 - Diagrama sintetizando o esquema de fracionamento rápido utilizado. 
filtrada e armazenada, era retirada da geladeira. Após equilíbrio com a temperatura ambiente, a amostra recebia ajuste para $\mathrm{pH}$ 2. Uma alíquota de $100 \mathrm{~mL}$ dessa amostra com $\mathrm{pH}$ corrigido era separada e acondicionada em frasco plástico de $100 \mathrm{~mL}$, sendo armazenada na geladeira a $4^{\circ} \mathrm{C}$ para análises posteriores de COD e de absorção em UV. Os $500 \mathrm{~mL}$ restantes eram encaminhados para a coluna DAX-8, procedendo-se ao

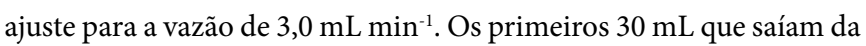
coluna eram descartados. Uma alíquota de $100 \mathrm{~mL}$ do efluente remanescente $(470 \mathrm{~mL})$ era recolhida e armazenada na geladeira $\left(4^{\circ} \mathrm{C}\right)$ para as análises subsequentes de COD e de absorção em UV. O pH do volume restante da amostra efluente da coluna de DAX-8 $(370 \mathrm{~mL})$ era medido, fazendo-se o ajuste a 2,0 quando necessário. Em seguida, regulava-se a vazão na coluna com a resina de XAD-4. O volume de $370 \mathrm{~mL}$ era então passado por essa coluna, descartando-se o primeiro volume de leito $(30 \mathrm{~mL})$. Após, $100 \mathrm{~mL}$ eram novamente coletados e armazenados na geladeira para as futuras análises. O volume remanescente, de $240 \mathrm{~mL}$, tinha o seu pH elevado a 8. Então, a coluna contendo a resina

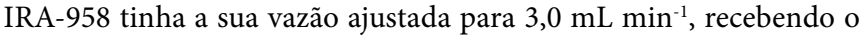
volume que havia passado na coluna de XAD-4 e com $\mathrm{pH}$ corrigido. Após o descarte do primeiro volume de $30 \mathrm{~mL}$, o efluente remanescente era recolhido em frasco plástico e armazenado na geladeira para posteriores análises de COD e de absorção em $\mathrm{UV}_{254}$.

\section{Cálculos de carbono orgânico dissolvido e de $\mathrm{UV}_{254}$}

Em cada coleta, após o término de todos os fracionamentos rápidos, as distintas subamostras de $100 \mathrm{~mL}$, armazenadas a $4^{\circ} \mathrm{C}$, foram encaminhadas para análises de COD e de absorção em UV. O COD foi calculado por meio da diferença entre os parâmetros carbono dissolvido total e carbono inorgânico total, medidos pelo analisador. Com base no conhecimento das concentrações de COD nos efluentes das colunas com as resinas, pôde-se calcular o valor de COD correspondente a cada fração da MON separada pelo fracionamento rápido, de acordo com as equações de 2 a 5 :

$\mathrm{AMH}=\mathrm{COD}_{\text {amostra original }}-\mathrm{COD}_{\text {amostra efluente da coluna de DAX-8 }}$

$\mathrm{ALH}=\mathrm{COD}_{\text {amostra efluente da coluna de DAX-8 }}-\mathrm{COD}_{\text {amostra efluente da coluna de XAD-4 }}$

$\mathrm{MHC}=\mathrm{COD}$ $-\mathrm{COD}$

$\mathrm{MHN}=\mathrm{COD}$ amostra efluente da coluna de IRA-958

\section{RESULTADOS E DISCUSSÃO}

\section{Características da água nos processos de tratamento}

Os resultados das características de qualidade da água medidas nos processos de tratamento na ETA Moinhos de Vento estão apresentados nas tabelas 3 e 4 . Os resultados completos de todas as análises estão disponíveis em Hillebrand (2017). De acordo com os resultados da ANOVA, fator duplo sem repetição, para as analises efetuadas, não foi identificada diferença estatisticamente significativa ( $p=0,767)$ entre as três coletas (27 de julho de 2016, 29 de agosto de 2016 e 13 de outubro de 2016). Entretanto, foi identificada diferença estatisticamente significativa $(p=0,017)$ entre os quatro tratamentos (água bruta, água decantada, filtro de areia e filtro de carvão ativado).

Como pode ser observado, houve reduções ao longo do tratamento dos parâmetros turbidez, cor, $\mathrm{pH}$, alcalinidade, $\mathrm{UV}_{254}$ e COD. O valor da turbidez diminuiu de modo considerável na água decantada em

Tabela 3 - Resultados das análises de turbidez, cor, pH e alcalinidade das distintas amostras de água (médias \pm desvios padrão).

\begin{tabular}{|c|c|c|c|c|}
\hline Amostra & Turbidez (NTU) & $\begin{array}{l}\text { Cor aparente } \\
\text { (mg L-1 Pt-Co) }\end{array}$ & $\mathrm{pH}$ & $\begin{array}{c}\text { Alcalinidade (mg L1 } \\
\left.\mathrm{CaCO}_{3}\right)\end{array}$ \\
\hline Água bruta & $57,20 \pm 17,60$ & $79,4 \pm 28,6$ & $6,98 \pm 0,14$ & $25,8 \pm 3,3$ \\
\hline Água decantada & $2,73 \pm 1,73$ & $9,6 \pm 5,0$ & $6,73 \pm 0,18$ & $20,1 \pm 2,9$ \\
\hline Após filtro de areia & $0,21 \pm 0,13$ & $3,3 \pm 0,6$ & $6,65 \pm 0,22$ & $17,3 \pm 2,0$ \\
\hline Após filtro de carvão ativado granular & $0,22 \pm 0,11$ & $2,9 \pm 0,3$ & $6,63 \pm 0,31$ & $13,8 \pm 2,4$ \\
\hline
\end{tabular}

NTU: nephelometric turbidity unit.

Tabela 4 - Resultados das análises de absorção de luz ultravioleta em 254 nm U(V ${ }_{254}$ ), carbono orgânico dissolvido (COD) e absorbância específica de luz ultravioleta (AEUV) das distintas amostras de água (médias \pm desvios padrão).

\begin{tabular}{l|c|c} 
Amostra & Absorção em UV ${ }_{254}\left(\mathrm{~cm}^{-1}\right)$ & COD (mg L-1) \\
\hline Água bruta & $0,177 \pm 0,033$ & $3,73 \pm 1,48$ \\
\hline Água decantada & $0,093 \pm 0,016$ & $2,46 \pm 1,43$ \\
\hline Após filtro de areia & $0,080 \pm 0,010$ & $0,76 \pm 0,59$ \\
\hline Após filtro de carvão ativado granular & $0,079 \pm 0,013 \pm 1,4$ & $14,0 \pm 6,7$ \\
\hline
\end{tabular}


comparação à água bruta. Uma parcela adicional da turbidez foi retida no filtro de areia. Assim como para a turbidez, houve forte redução da cor aparente na água decantada (88\%). Observou-se que houve remoção adicional de cor pelo carvão ativado. Houve pequena redução do $\mathrm{pH}$ na água decantada em relação à água bruta. A ETA usa cloreto de polialumínio (CPA) como coagulante, que já se encontra na forma hidrolisada e não deve resultar em mudanças de $\mathrm{pH}$, de maneira diferente dos coagulantes metálicos convencionais. Houve diminuição de $22 \%$ na concentração de alcalinidade da água decantada em relação à água bruta. Houve também reduções nas alcalinidades dos filtros de areia (14\%) e de CAG (20\%).

Houve diminuição de $47 \%$ da absorção em $U_{254}$ na água decantada em comparação à água bruta. Edzwald e Tobiason (2011) relatam que a absorção em $\mathrm{UV}_{254}$, em águas naturais, varia de $0,04 \mathrm{~cm}^{-1}$, para baixas concentrações de carbono orgânico total e matéria húmica, até $0,8 \mathrm{~cm}^{-1}$, para águas com teores maiores de matéria orgânica. Segundo esses autores, a maior parte das águas contém entre 0,07 e $0,3 \mathrm{~cm}^{-1}$. A absorção em UV na água do Guaíba, que serve a ETA Moinhos de Vento, encontra-se nessa faixa. Os valores de absorbância em 254 nm foram praticamente os mesmos entre as águas dos filtros de areia e de CAG. Esse dado indica baixa remoção de matéria orgânica que é absorvida nesse comprimento de onda, como as substâncias húmicas. A água bruta da ETA apresentou concentrações médias de COD de 3,73 $\mathrm{mg} \mathrm{L}^{-1}$, reduzindo para 2,46 $\mathrm{mg} \mathrm{L}^{-1}$ na água decantada, 0,76 e $0,62 \mathrm{mg} \mathrm{L}^{-1}$ nos efluentes dos filtros de areia e de CAG. Chama a atenção o decréscimo de $69 \%$ no COD do efluente do filtro de areia em relação à água decantada. Em princípio, a filtração não deve mudar a concentração de COD da água, uma vez que apenas material particulado coloidal é retido no filtro (SILLANPÄÄ, 2015). Contudo, neste estudo, as diminuições foram consideráveis nas três amostras coletadas, em meses diferentes. Na primeira, segunda e terceira coletas, as reduções de COD foram, respectivamente, de 65, 75 e 74\%. Estava ocorrendo um processo que causava a redução do COD no filtro de areia. Uma hipótese é a adição de cloro que é realizada na ETA antes do filtro de areia, o que poderia oxidar uma parte da matéria orgânica dissolvida (MOD) presente. As coletas de água decantada foram realizadas antes da intercloração. Para comprovar essa hipótese, seria necessário também coletar amostras de água decantada após a intercloração, o que não foi feito neste trabalho.
Os valores de AEUV foram superiores a 4, com tendência crescente ao longo das etapas do tratamento. Contudo, o que se espera é a redução de AEUV ao longo do tratamento, com valores inferiores a 2 na água tratada (EDZWALD; TOBIASON, 2011). Uma possível explicação para esses valores altos de AEUV é a maior diminuição das concentrações de COD (que está no denominador da Equação 1 de AEUV) ao longo dos processos de tratamento em comparação a redução nos valores da absorção de UV (que está no numerador da Equação 1). Na Tabela 4, observa-se que a diminuição dos valores da absorção em UV entre a água decantada e o filtro de areia foi de $14 \%$, enquanto a redução nas concentrações de COD foi de $69 \%$ (quase cinco vezes maior).

\section{Resultados do fracionamento rápido}

\section{Absorção em luz ultravioleta}

Nos resultados apresentados a seguir, as amostras referem-se à água bruta, à água decantada, à água após a filtração em areia e à água após filtração em CAG. Cada amostra tem subamostras denominadas: original (antes de passar pelas colunas com as resinas), efluente de DAX-8, efluente de XAD-4 e efluente de IRA-958. A Tabela 5 mostra as médias e os desvios padrões das análises de absorção em UV, para as subamostras de água bruta, água decantada, filtro de areia e filtro de CAG. Nas Figuras 2A e 2B, esses valores estão apresentados em gráficos.

Como pode ser constatado na Tabela 5 e na Figura 2A, as amostras originais (antes do fracionamento) tiveram os maiores valores de absorção em $\mathrm{UV}_{254}$. Isso ocorreu porque as resinas DAX-8, XAD-4 e IRA-958 adsorveram a MOD no decorrer do fracionamento, diminuindo o valor de absorção em $\mathrm{UV}_{254}$. Nas subamostras efluentes de DAX-8, houve redução dos valores de absorção em $U_{254}$, com relação às amostras originais, para $60 \%$ (água bruta), 33\% (água decantada), $30 \%$ (filtro de areia) e 32\% (filtro de CAG). Essas reduções indicam que as amostras possuem a fração de $\mathrm{AMH}$ de MON. As atenuações da absorção em $U_{254}$ entre as amostras efluentes de DAX-8, XAD-4 e IRA-958 foram bem menores entre si, dado que significa predomínio da fração de MHN. Na Tabela 5 e na Figura 2B, observa-se diferença de $47 \%$ entre a absorção em $U_{254}$ da amostra original da água bruta e da água decantada, indicando a eficiência dos processos de coagulação, floculação e sedimentação. As outras subamostras dos efluentes

Tabela 5 - Valores da absorção em luz ultravioleta ao comprimento de onda de 254 nm nas distintas subamostras de água, do fracionamento rápido (médias \pm desvios padrão).

\begin{tabular}{l|c|c|c}
\hline Absorção em UV ${ }_{254}\left(\mathrm{~cm}^{-1}\right)$ & Amostra original & Efluente de DAX-8 & Efluente de XAD-4 \\
\hline Água bruta & $0,177 \pm 0,033$ & $0,071 \pm 0,005$ & $0,057 \pm 0,001$ \\
\hline Água decantada & $0,093 \pm 0,016$ & $0,062 \pm 0,005$ & $0,052 \pm 0,002$ \\
\hline Após filtro de areia & $0,080 \pm 0,010$ & $0,056 \pm 0,004$ & $0,049 \pm 0,002$ \\
\hline Após filtro de carvão ativado granular & $0,079 \pm 0,013$ & $0,054 \pm 0,004$ & $0,048 \pm 0,002$ \\
\hline
\end{tabular}


das resinas tiveram pequenas variações, havendo, portanto, predominância da fração de MHN entre elas.

\section{Carbono orgânico dissolvido}

Os valores das médias e dos desvios padrões das análises de COD para as diferentes frações de $\mathrm{MON}$ separadas no fracionamento rápido estão apresentados na Tabela 6. As Figuras 3A e 3B ilustram esses valores de forma gráfica.

A legenda da Tabela 6 indica que alguns resultados foram desconsiderados. Isso porque algumas inconsistências foram observadas, como concentrações negativas de COD. Foram usadas duas curvas de calibração com concentrações entre 0,1 e $0,5 \mathrm{mg} \mathrm{L}^{-1}$ e entre 0,5 e $10 \mathrm{mg} \mathrm{L}^{-1}$, ambas com coeficientes de determinação superiores a 0,99. A aplicação da curva de calibração de menor faixa de concentrações resultou em alguns valores negativos de COD. Em alguns casos, o efluente da coluna tinha concentração de COD maior que o da amostra original (antes de passar pelas colunas com as resinas), o que foi julgado inconsistente. Isso ocorreu para concentrações de COD próximas a zero, sobretudo nas frações de MHC e de MHN do efluente do filtro de areia.

Na Tabela 6 e na Figura 3B, observa-se que as frações de AMH e de ALH predominaram na amostra de água bruta, enquanto a fração de MHN foi a de menor valor médio de COD. Na água decantada, as frações de AMH e de ALH continuaram predominantes, mas foram reduzidas, respectivamente, a 44 e $26 \%$ em relação à água bruta. Não foi
A

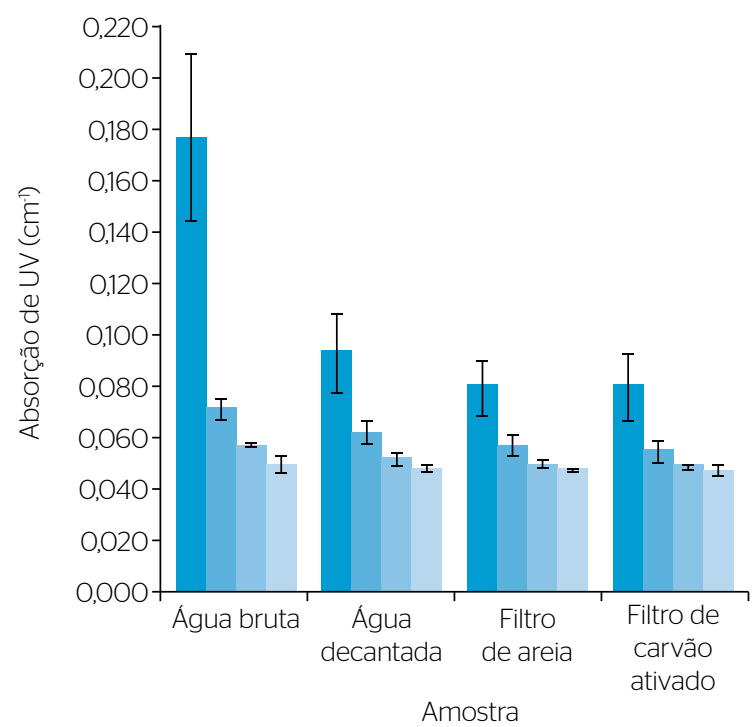

$\begin{array}{llll}\text { Amostra } & \text { Efluente } & \text { Efluente } & \text { Efluente } \\ \text { original } & \text { de DAX-8 } & \text { de XAD-4 } & \text { de IRA-958 }\end{array}$
B

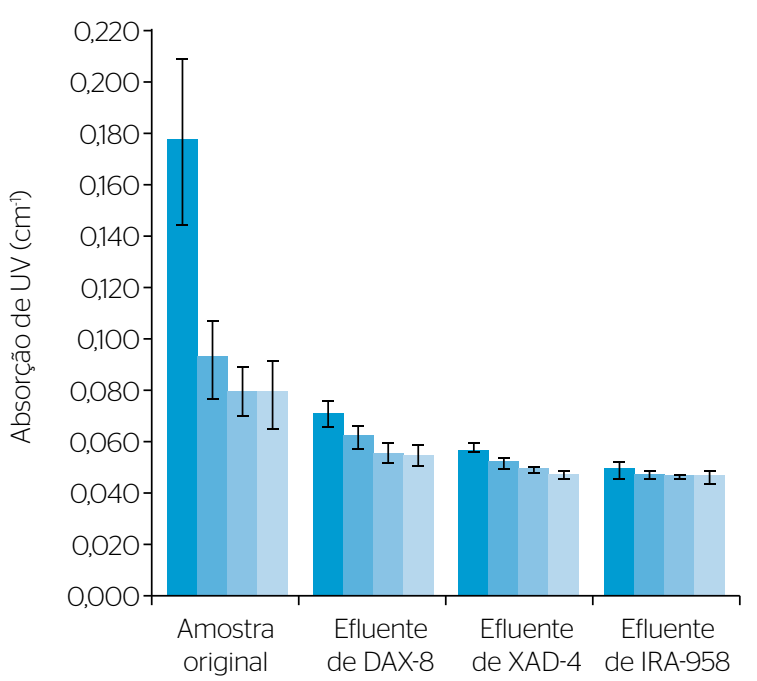

Subamostra

Água bruta

Água $\quad$ Filtro decantada de areia

Filtro de carvão ativado

Figura 2 - Valores médios e desvios padrão da absorção em $U_{254}(A)$ nas subamostras da água bruta, da água decantada e dos efluentes dos filtros de areia e de carvão ativado granular (CAG) e (B) na amostra original e nos efluentes de DAX-8, XAD-4 e IRA-258 na água bruta, na água decantada e nos efluentes dos filtros de areia e de CAG.

Tabela 6 - Resultados das análises de carbono orgânico dissolvido nas distintas frações de matéria orgânica natural separadas no fracionamento rápido (médias \pm desvios padrão).

\begin{tabular}{|c|c|c|c|c|}
\hline $\begin{array}{l}\text { COD } \\
\left(\mathrm{mg} \mathrm{L}^{-1}\right)\end{array}$ & Água bruta & Água decantada & Após filtro de areia & Após filtro de CAG \\
\hline COD total & $3,73 \pm 1,48$ & $2,46 \pm 1,43$ & $0,76 \pm 0,59$ & $0,62 \pm 0,75$ \\
\hline ALH & $1,29 \pm 0,11$ & $0,95 \pm 0,57$ & $0,22^{\star \star}$ & $0,22 \pm 0,31^{\star \star \star}$ \\
\hline $\mathrm{MHC}$ & $0,11 \pm 0,03$ & $0 \pm 0$ & $\mathrm{O}^{* *}$ & $0,08 \pm 0,11^{* * *}$ \\
\hline
\end{tabular}

*Nenhuma das três amostras foi considerada; **uma das três amostras foi considerada; ${ }^{* *}$ duas das três amostras foram consideradas; COD: carbono orgânico dissolvido; AMH: ácidos muito hidrofóbicos; ALH: ácidos levemente hidrofóbicos; MHC: matérias hidrofílicas carregadas; MHN: matérias hidrofílicas neutras. 
detectada a presença de MHC na água decantada, mas a fração MHN esteve presente em concentrações baixas $\left(0,23 \mathrm{mg} \mathrm{L}^{-1}\right)$. O filtro de areia reduziu em $47 \%$ a concentração de COD dos AMH em relação à água decantada. Já a concentração de COD da fração de AMH no efluente do filtro de CAG diminuiu 63\% em comparação ao filtro de areia (de 0,68 para $\left.0,25 \mathrm{mg} \mathrm{L}^{-1}\right)$. As concentrações médias de COD das frações de AMH e de ALH no efluente do filtro de CAG foram, respectivamente, 83 e $89 \%$ menores do que as concentrações de COD na água bruta. Esses resultados estão próximos daqueles descritos por Urbanowska e Kabsch-Korbutowicz (2016), que observaram redução de $82 \%$ para AMH no tratamento constituído de coagulação, floculação, sedimentação, filtração em areia, ozonização e adsorção em filtro CAG. Para $\mathrm{ALH}$, os autores mediram diminuição de $57 \%$, menor, portanto, da encontrada neste estudo. Segundo Eikebrokk, Juhna e Østerhus (2006), a sequência de remoção de COD na coagulação é $\mathrm{AMH}>\mathrm{ALH}=\mathrm{MHC}$ $>$ MHN. Na água clarificada, observou-se maior redução dos AMH em relação aos ALH, contudo a relação com MHC foi dificultada pela baixa concentração dessa fração na amostra de água bruta $(0,11 \mathrm{mg}$ $\left.\mathrm{L}^{-1}\right)$. Em contrapartida, não houve diminuição de MHN, o que é compatível com o estudo dos autores citados.

Para a fração de MHC, os valores médios de COD decresceram a zero $\mathrm{mg} \mathrm{L}^{-1}$ na amostra de água decantada e mantiveram-se próximos a zero $\mathrm{mg} \mathrm{L}^{-1}$ nos efluentes dos filtros de areia e de CAG. Mesmo para água bruta, a concentração de MHC foi baixa $\left(0,11 \mathrm{mg} \mathrm{L}^{-1}\right)$. Urbanowska e Kabsch-Korbutowicz (2016) observaram redução de 66\% para a fração de MHC no tratamento de água que estudaram.

As frações de MHN nas amostras de água bruta foram próximas a zero. Entretanto, essas frações foram identificadas na água decantada e no efluente do filtro CAG em concentrações baixas. Urbanowska e Kabsch-Korbutowicz (2016) citam que é difícil remover a fração de MHN da água, por ela ser formada por materiais hidrofílicos eletricamente inertes. Por sua vez, Eikebrokk (2009) menciona que as frações de AMH e de ALH podem ser convertidas em MHN durante o tratamento da água.

A Figura 4 mostra os percentuais de remoção das frações de $\mathrm{AMH}$, $\mathrm{ALH}, \mathrm{MHC}$ e MHN após o filtro de CAG em relação à água bruta na ETA. As frações de AMH e de ALH reduziram entre 80 e 90\% em relação à água bruta. A concentração de COD da fração de $\mathrm{MHN}$ no efluente do filtro de CAG foi superior ao da água bruta, contudo, ressalta-se que os valores medidos de COD dessa fração foram próximos a zero.

A Figura 5 apresenta a composição das frações de AMH, ALH, MHC e MHN, medidas em COD, na água bruta, decantada e em filtro de CAG. Não é mostrada a composição dessas frações para o efluente do filtro de areia em virtude da limitação anteriormente relatada.

As frações dominantes na água bruta foram de AMH e de ALH, somando $96 \%$ da composição de COD total. Esses valores diferem
A

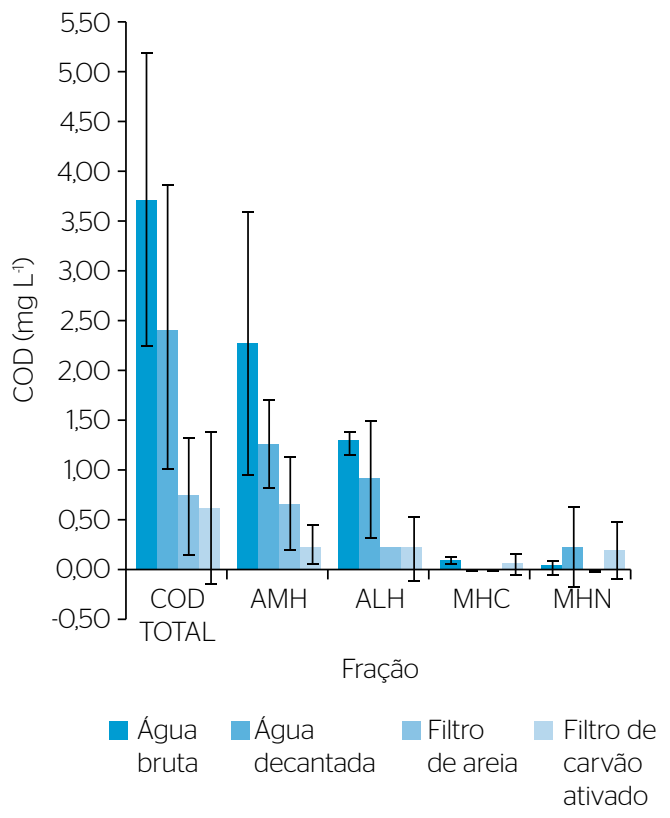

B

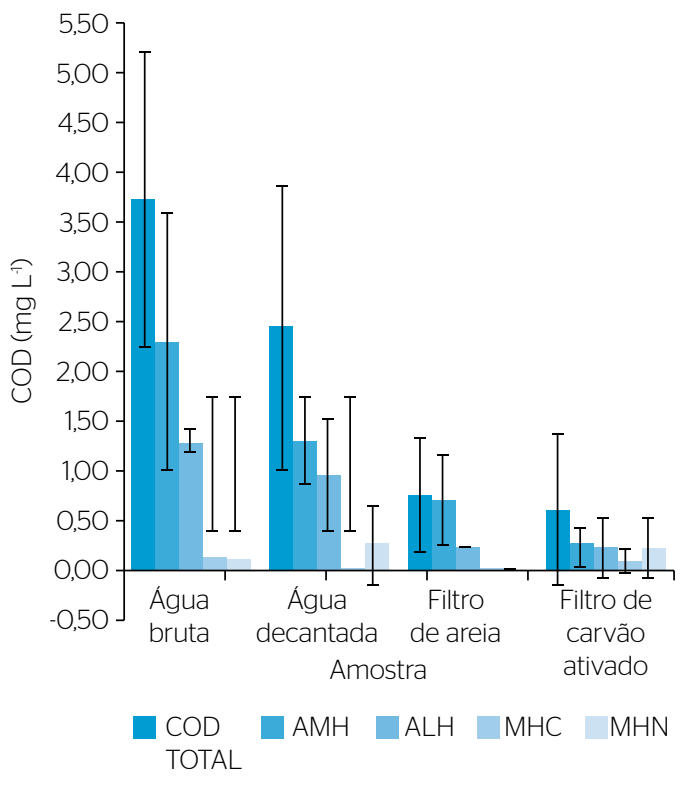

Figura 3 - Concentrações médias e desvios padrão de carbono orgânico dissolvido (COD) (A) na água bruta, decantada, efluentes de filtros de areia e de carvão ativado granular (CAG) nas frações de ácidos muito hidrofóbicos (AMH), ácidos levemente hidrofóbicos (ALH), matérias hidrofílicas carregadas (MHC) e matérias hidrofílicas neutras (MHN) e (B) das frações de AMH, ALH, MHC e MHN nas amostras de água bruta, decantada, efluentes de filtros de areia e de CAG. 
dos encontrados por Urbanowska e Kabsch-Korbutowicz (2016), que mediram 56\% na soma de AMH e ALH na água bruta. Isso significa a predominância de ácidos húmicos e fúlvicos no ponto de captação de água no Guaíba, o que ocorre também em outras fontes de captação de água (CHOW; FABRIS; DRIKAS, 2004; EIKEBROKK; JUHNA; ØSTERHUS, 2006; MATILAINEN et al., 2011; SILLANPÄÄ, 2015). $\mathrm{Na}$ água decantada, a presença de AMH e de ALH continuou predominante, somando 91\% da concentração de COD total. A fração de MHN cresceu para 10\% e a de MHC não foi detectada. Após o filtro de CAG, a contribuição percentual de $\mathrm{MHN}$ aumentou para $27 \%$, enquanto a de MHC passou a representar 10\% do COD. As frações de AMH e de ALH

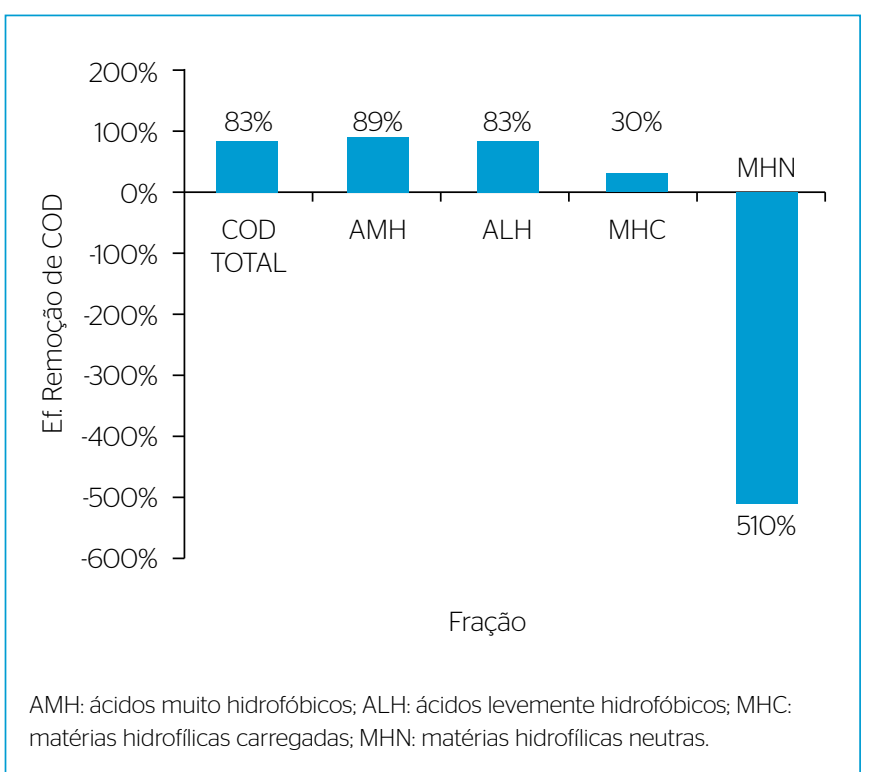

Figura 4 - Eficiência (Ef.) de remoção de carbono orgânico dissolvido (COD) e frações do fracionamento rápido após filtro de carvão ativado em relação à água bruta na estação de tratamento de água (ETA) Moinhos de Vento. decresceram para $62 \%$, tendo sido provavelmente removidas da água ou convertidas, de modo parcial, na fração de MHN, o que é descrito em Eikebrokk (2009) e em Urbanowska e Kabsch-Korbutowicz (2016).

\section{CONCLUSÕES}

A concentração de COD no efluente do filtro de areia foi $80 \%$ menor que a concentração na água bruta $\left(0,76 \mathrm{mg} \mathrm{L}^{-1}\right.$ e $3,73 \mathrm{mg} \mathrm{L}^{-1}$, respectivamente). O efluente do filtro de CAG apresentou concentração de COD $18 \%$ menor que no efluente do filtro de areia. A absorção em UV foi reduzida em 55\% nos efluentes dos filtros de areia e de CAG em relação à água bruta. A maior redução de COD em relação à absorção em UV explica o aumento dos valores da AEUV ao longo dos processos de tratamento.

No fracionamento rápido, os valores de absorção em $\mathrm{UV}_{254}$ decresceram de $0,177 \mathrm{~cm}^{-1}$ na água bruta para $0,071,0,057 \mathrm{e} 0,049 \mathrm{~cm}^{-1}$, respectivamente, nos efluentes das colunas com as resinas DAX-8, XAD-4 e IRA-958. O mesmo padrão foi verificado para as amostras de água decantada e os efluentes dos filtros de areia e de CAG. Na água estudada, os AMH foram os principais contribuintes para o COD, seguidos pelos ALH. Ambas as frações foram as que tiveram maiores reduções ao longo das etapas do tratamento de água. As parcelas de MHC e de MHN tiveram concentrações de COD próximas a zero na maior parte das amostras analisadas.

Este estudo pode ser expandido para águas de outras bacias hidrográficas com diferentes características e com composição de águas naturais. A técnica do fracionamento também pode ser aplicada considerando outros processos de tratamento, por exemplo, o uso do ozônio associado ao CAG. A depender da disponibilidade de equipamentos analíticos, é possível determinar os compostos que formam as frações de AMH, ALH, MHC e MHN, assim como seus pesos moleculares.

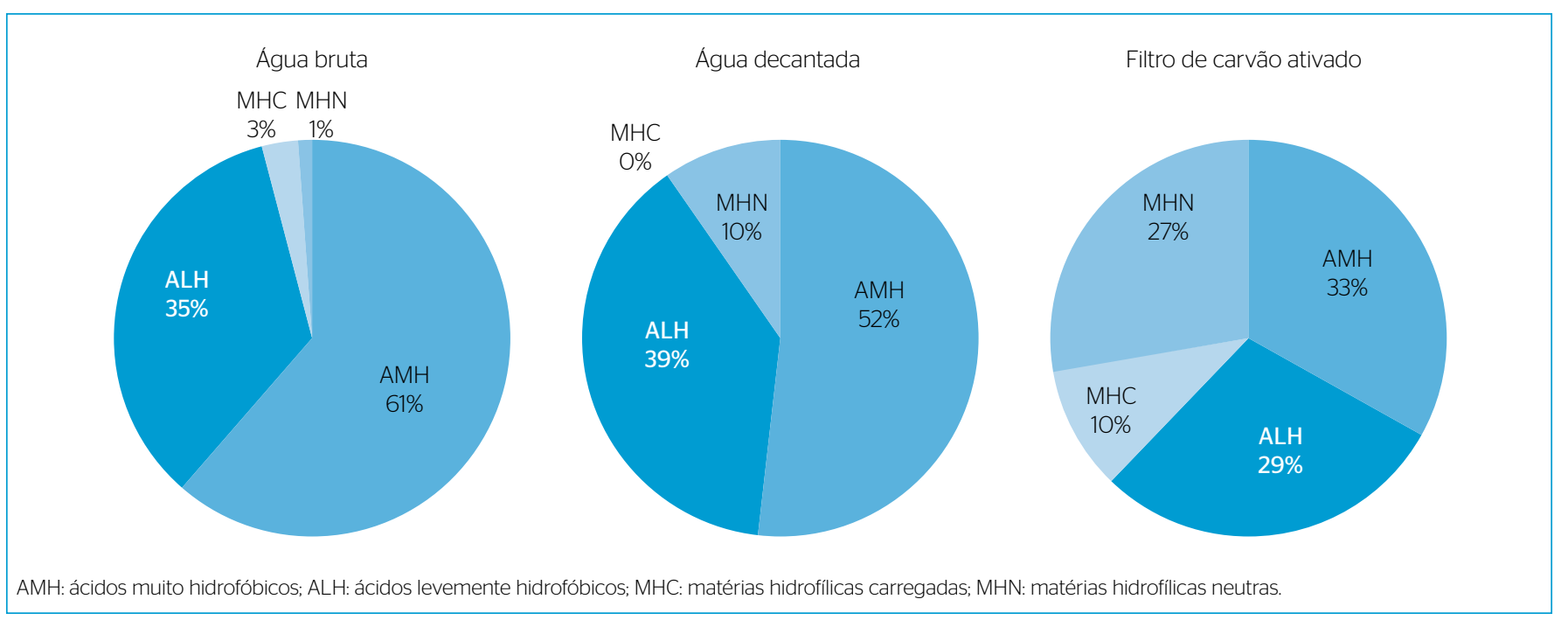

Figura 5 - Composição e carbono orgânico dissolvido (COD) total das frações de matéria orgânica dissolvida (MOD) nas amostras de água bruta, decantada e efluente do filtro de carvão ativado. 


\section{REFERÊNCIAS}

AMERICAN PUBLIC HEALTH ASSOCIATION (APHA); AMERICAN WATER WORKS ASSOCIATION (AWWA); WATER ENVIRONMENT FEDERATION (WEF). (2O12) Standard methods for the examination of water and wastewater. 22. ed. Washington, D.C.: American Water Works Association. 1496 p.

BOND, T; GOSLAN, E.H.; PARSONS, S.A.; JEFFERSON, B. (2O11) Treatment of disinfection by-product precursors. Environmental Technology, v. 32, n. 1, p. 1-25. https://doi.org/10.1080/09593330.2010.495138

CHOW, C.W.K.; FABRIS, R.; DRIKAS, M. (2004) A rapid fractionation technique to characterize natural organic matter for the optimisation of water treatment processes. Journal of Water Supply: Research and Technology, v. 53, n. 2, p. 85-92. https://doi.org/10.2166/aqua.2004.0008

CHOW, C.W.K; FABRIS, R; WILKINSON, K; FITZGERALD, F; DRIKAS, M. (2006) Characterising NOM to assess treatability. Water, v. 33, n. 2, p. 36-42.

CRITTENDEN, J.C.; TRUSSELL, R.R.; HAND, D.W.; HOWE, K.J.; TCHOBANOGLOUS, G. (2012) MWH's water treatment: principles and design. 3. ed. Hoboken: John Wiley \& Sons. 1901 p.

DEPARTAMENTO MUNICIPAL DE ÁGUA E ESGOTOS (DMAE). (2O12) A ocorrência de florações no lago Guaíba. Porto Alegre: DMAE. Disponível em: <lproweb.procempa.com.br/pmpa/prefpoa/cs/usu_doc/ ocorrencia_de_floracoes_lago_guaiba.pdf>. Acesso em: 10 out. 2018.

DORNELES, N.A.; MIDUGNO, R.; RODRIGUES, A.L.M. (2017) Avaliação da carga orgânica e de nutrientes na qualidade das águas em porção da margem leste do lago Guaíba, Rio Grande do Sul, Brasil. FEPAM em Revista, v. 11, p. 58-72.

EDZWALD, J.K; TOBIASON, J.E. (2011) Chemical principles, source water, composition, and watershed protection. In: EDZWALD, J.K. (org.). Water quality \& treatment: a handbook on drinking water. 6. ed. Nova York: McGraw-Hill. 1696 p. cap. 3.

EIKEBROKK, B. (2009) Water treatment: optimization with respect to what? In: HOVEN, T.V.D.; KAZNER, C. (orgs.). TECHNEAU: Safe drinking water from source to tap - State of the art \& perspectives. Londres: IWA Publishing. p. 265-280.

EIKEBROKK, B.; JUHNA, T.; ØSTERHUS, S.W. (2006) Water treatment by enhanced coagulation: operational status and optimization issues. TECHNEAU. 110 p.

GIBERT, O.; LEFĖVRE, B.; FERNÁNDEZ, M.; BERNAT, X.; PARAIRA, M.; PONS, M. (2013) Fractionation and removal of dissolved organic carbon in a full-scale granular activated carbon filter used for drinking water production. Water Research, v. 47, n. 8, p. 2821-2829. https://doi.org/10.1016/j.watres.2013.02.028

HILLEBRAND, F. (2017) Caracterização da matéria orgânico dissolvida em processos de tratamento de água para consumo humano através do uso da técnica do fracionamento rápido. 97f. Dissertação (Mestrado em Recursos Hídricos e Saneamento Ambiental) Universidade Federal do Rio Grande do Sul, Porto Alegre.
MATILAINEN, A.; GJESSING, E.T.; LAHTINEN, T.; HED, L.; BHATNAGAR, A.; SILLANPÄÄ, M. (2011) An overview of the methods used in the characterization of natural organic matter (NOM) in relation to drinking water treatment. Chemosphere, v. 83, n. 11, p. 1431-1442. https://doi.org/10.1016/j.chemosphere.2011.01.018

MATILAINEN, A.; VEPSÄLÄINEN, M.; SILLANPÄÄ, M. (2010) Natural organic matter removal by coagulation during drinking water treatment: a review. Advances in Colloid and Interface Science, v. 159, n. 2, p. 189-197. https://doi.org/10.1016/j.cis.2010.06.007

PREFEITURA DE PORTO ALEGRE (PMPA). (2013) Departamento Municipal de Água e Esgoto. Plano Municipal de Saneamento Básico: modalidade - abastecimento de água. Porto Alegre: DMAE. $174 \mathrm{p}$

SILLANPÄÄ, M. (2015) Natural organic matter in water: characterization and treatment methods. Amsterdam: Elsevier. $382 \mathrm{p}$.

SWIETLIK, J.; DABROWSKA, A.; RACZYK-STANISLAWIAK, U.; NAWROCKI, J. (2004) Reactivity of natural organic matter fractions with chlorine dioxide and ozone. Water Research, v. 38, n. 3, p. 547558. https://doi.org/10.1016/j.watres.2003.10.034

TEIXEIRA, M.B. (2014) Remoção de carbono orgânico dissolvido de águas de abastecimento por adsorção em carvão ativado granular. 75f. Dissertação (Mestrado em Recursos Hídricos e Saneamento Ambiental) - Universidade Federal do Rio Grande do Sul, Porto Alegre.

THURMAN, E.M. (1985) Organic geochemistry of natural waters. Dordrecht: Martinus Nijhoff/Dr. W. Junk.

TREGUER, R.; TATIN, R.; COUVERT, A.; WOLBERT, D.; TAZI-PAIN, A. (2010) Ozonation effect on natural organic matter adsorption and biodegradation - Application to a membrane bioreactor containing activated carbon for drinking water production. Water Research, v. 44, n. 3, p. 781-788. https://doi.org/10.1016/j. watres.2009.10.023

URBANOWSKA, A.; KABSCH-KORBUTOWICZ, M. (2016) Characteristics of natural organic matter removed from water along with its treatment. Environment Protection Engineering, v. 42, n. 2, p. 183-195. http://dx.doi.org/10.5277\%2Fepe160213

VIEIRA, R.F.; BERENGUEL, A.T.; SILVA, M.A.; VILAÇA, J.S.; DOMINGUES, V.F.; FIGUEIREDO, S.A. (2012) Natural organic matter fractionation along the treatment of water for human consumption. Global NEST Journal, v. 14, n. 4, p. 399-406. https:// doi.org/10.30955/gnj.000828

WESTPHALEN, A.P.C.; BENETTI, A.D. (2016) Determinação da matéria orgânica natural (MON) pela técnica do fracionamento rápido: Procedimento Operacional Padrão (POP). Porto Alegre: Universidade Federal do Rio Grande do Sul. 20 p. 